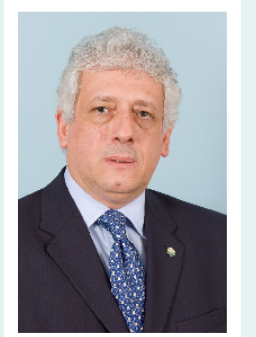

\title{
Continuing Education,
} Internationalization of Brazilian Cardiology and Participation in the Creation of Health Care Policies

\author{
Antonio Carlos Palandri Chagas \\ President of SBC
}

As the end of this first year as the President of the Brazilian Society of Cardiology (Sociedade Brasileira de Cardiologia - SBC) draws near, I take the opportunity to appraise these 12 months of work. And, in doing so, I emphasize the tripod on which our term has been supported, directed mainly at promoting continuing education of good quality, the internationalization of the Brazilian Cardiology and the participation of SBC in the creation of health care policies.

I took the responsibility of ensuring the spreading of knowledge at the moment I became the President of SBC. I can cite many of the initiatives directed to that purpose, from state and regional scientific meetings, department and study group events - for 2009, there are more than 40 sessions already planned - to refreshing courses and promoting ACLS (Advanced Cardiac Life Support) trainings, without forgetting to mention the biggest forum of all: the Brazilian Congress of Cardiology.

It is important to stress that these actions were carried out in a decentralized way, in order to promote the development of Cardiology throughout the country. We strove to get close to our representatives. Through the "Always Present SBC" Project, we guaranteed the participation of members of the Board and the staff of SBC at the several events that took place throughout the year with the objective of supporting them, but mainly to get to know their needs.

The same program allowed our presence at the main international forums in the area, such as the meetings of the American College of Cardiology, the Portuguese Society of Cardiology, the World Heart Federation, the Spanish Society of Cardiology and the American Heart Association. In some of them, SBC participated in their scientific programs, through joint meetings.

On the other hand, these sessions were carried out at the $63^{\text {rd }}$ Brazilian Congress of Cardiology, confirming the international status of the meeting and they have been confirmed for the next convention, which will take place on September 12-16, 2009, in the city of Salvador, state of Bahia. These initiatives comprise the action plan for SBC to take the lead in South-American cardiology.

An important step that has been taken and one that will make the Society move toward this direction, which is the Spanish version of the Brazilian Archives of Cardiology. The electronic version in the new language, in addition to the one in the English language, will be available as of this month. It will be officially announced during the commemorative ceremony to celebrate the $60^{\text {th }}$ anniversary of the Journal and the IV ABC Scientific Publication Award, which will be held in Sao Paulo, on December 6.

However, globalization is not the only path that national cardiology follows. We are working together with the Ministry of Health, with whom we signed a Term of Technical Cooperation. The formalization of this partnership is the result of a series of actions undertaken by this Board of Directors to positively interfere in the creation of public policies of cardiovascular health. And, in addition to the participation of SBC in these projects, the agreement shows that the Federal Government acknowledges the importance of SBC.

And this acknowledgement is not unwarranted: we have extensively promoted the need for prevention, with the objective of being able to reverse the high incidence of cardiovascular diseases in Brazil, which currently kill almost 300,000 people every year. We face the effort to improve the health conditions of the Brazilian people and to prevent projections, such as the one by the World Health Organization (WHO) that Brazil will be, in 2040, the country with the highest incidence of cardiovascular diseases in the world. The challenge pertains to all of us. Count on SBC to do it!

Merry Christmas and a Successful New Year!

Mailing address: Antonio Carlos Palandri Chagas •

Avenida Marechal Câmara, 160/330, Centro - 20020-907, Rio de Janeiro, RJ - Brazil

E-mail: acchagas@cardiol.br 